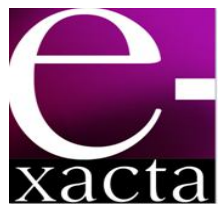

ISSN: 1984-3151

\title{
EMPREENDEDORISMO SUSTENTÁVEL: O VALOR DE NEGÓCIOS AMBIENTAIS
}

\author{
SUSTAINABLE ENTREPRENEURSHIP: VALUE BUSINESS ENVIRONMENT
}

\author{
Janaina Lorena Moreira'; Laisy Garcia Ribeiro Lima; \\ Leila Said Tótaro ${ }^{3}$ \\ 1 Graduada em Engenharia Química pelo Centro Universitário \\ de Belo Horizonte - Unibh, em 2013. Belo Horizonte. Minas \\ Gerais, Brasil. janalmoreira@hotmail.com. \\ 2 Graduada em Engenharia Química pelo Centro Universitário \\ de Belo Horizonte - Unibh, em 2013. Belo Horizonte. Minas \\ Gerais, Brasil. laisy lima@hotmail.com. \\ 3 Especialista em Administração e Marketing pela \\ Universidade Fumec, em 1996. Belo Horizonte. Minas \\ Gerais, Brasil. leilasaidtotaro@hotmail.com.
}

Recebido em: 20/09/2013 - Aprovado em: 29/11/2013 - Disponibilizado em: 30/11/2013

RESUMO: O panorama atual vivenciado pela sociedade sugere uma árdua missão de promover a mudança por parte dos cidadãos e dos empreendedores, e isso incide sobre uma reinvenção dos padrões de produção e consumo adotados pela população. Assim sendo, são necessárias novas formas de organização, como o empreendedorismo sustentável. Proposição que inova e desafia os empreendedores a respeito da necessidade de conciliar os parâmetros econômicos, ambientais e sociais nos negócios. Este trabalho, então, buscou evidenciar como o empreendedorismo sustentável pode ser uma alternativa de novos negócios. A sua metodologia trata-se de uma investigação de natureza descritiva, cuja ferramenta de coleta de dados foi as entrevistas. Conclui-se que, através de atitudes inovadoras de desenvolvimento sustentável, o empreendedorismo sustentável pode ser uma oportunidade de novos negócios, gerando receitas e contribuindo para a continuidade dos negócios.

PALAVRAS-CHAVE: Empreendedorismo ambiental. Novos negócios. Valor.

ABSTRACT: The current situation experienced by society suggests an arduous mission to promote change by citizens and entrepreneurs and it focuses on a reinvention of the patterns of production and consumption adopted by the population. Therefore, we need new forms of organization, such as sustainable entrepreneurship. Proposition that innovates and challenges entrepreneurs about the need to reconcile economic parameters, environmental and social considerations into business. This study attempts to show how sustainable entrepreneurship can be an alternative new business. Its methodology, it is an investigation of a descriptive nature, whose tool of data collection were interviews. We conclude that, through innovative attitudes of sustainable development, sustainable entrepreneurship can be an opportunity for new business, generating income and contributing to business continuity.

KEYWORDS: Environmental entrepreneurship. New business. Value.

\section{INTRODUÇÃO}

No mundo capitalista globalizado, no qual os valores fundamentais e princípios econômicos estão intrinsicamente ligados ao consumismo, aparecem diversos problemas advindos desse costume, como a crescente produção de resíduos sólidos urbanos e, consequentemente, seu tratamento e armazenamento inadequado, o que gera problemas ecológicos preocupantes. 
Além dos danos causados ao meio ambiente, o aumento na produção de resíduos vem comprometendo significativamente a qualidade de vida dos habitantes das cidades, sejam estas grandes ou pequenas.

As desigualdades nos níveis de desenvolvimento nos países do mundo apresentam-se como um amplo obstáculo na implementação de ações ambientais, bem como na proteção do meio ambiente. Em dados atuais, segundo Pimentel (2008), 25\% da população mundial consomem $85 \%$ da madeira, $75 \%$ dos metais, $75 \%$ da energia produzida e $60 \%$ do alimento produzido no mundo. O consumo por habitante em um país rico é equivalente, pelo menos, ao consumo de 25 habitantes de um país emergente. Perante essa realidade consumista, as nações têm avaliado politicas e práticas aplicadas ao desenvolvimento que adotem os requisitos ambientais sustentáveis.

Segundo Carlos Vieira da Silva Filho, diretor executivo da ABRELPE - Associação Brasileira das Empresas de Limpeza Pública e Resíduos Especiais -, no Brasil, $45 \%$ dos resíduos sólidos urbanos, que correspondem a 67 mil toneladas/dia, são despachados para lixões a céu aberto e outras destinações impróprias. Além disso, aproximadamente $20 \mathrm{mil}$ toneladas/dia, ao menos, são recolhidas e, por fim, vão parar em terrenos baldios e córregos. Não obstante, em 2 de agosto de 2010, foi sancionada a Lei 12.305 de Política Nacional de Resíduos Sólidos (PNRS), que constitui princípios, instrumentos, objetivos e diretrizes visando promover e garantir uma gestão adequada dos resíduos sólidos nos municípios.

Já o estado de Minas Gerais, segundo a FEAM (2010), desde 2003, quando foi implantado o Programa "Minas sem Lixões" pela Fundação Estadual de Meio Ambiente, vem se apresentando acima da média nacional no acondicionamento adequado de resíduos sólidos urbanos (RSU), uma vez que conseguiu restringir a, aproximadamente,
$50 \%$ o número de lixões, além de aumentar em $500 \%$ e $300 \%$ o número de aterros sanitários e usinas de triagem e compostagem, respectivamente.

Em Belo Horizonte e na região metropolitana, encontram-se várias empresas atuando na área de reciclagem de RSU. Com intuito de preservar o meio ambiente, as empresas de reciclagem se dividem em diferentes setores, de acordo com seu tipo de resíduo. Seguindo essa linha do pensamento sustentável, atualmente, tem-se falado muito em empreendedorismo ambiental, uma vez que promove ações inovadoras no setor de proteção ambiental agregando valor aos negócios.

E um grande exemplo de empreendedorismo ambiental em Belo Horizonte é a Associação dos Catadores de Papel e Material Reaproveitável (ASMARE), que tem como objetivo promover a organização das centenas de milhares de homens e mulheres que batalham nas ruas, dia e noite, para garantir a própria sobrevivência e consequentemente impedir que o lixo se acumule e a poluição aumente. Localizada na região central de Belo Horizonte, a ASMARE é responsável pela coleta, triagem, prensagem e comercialização de toneladas de materiais recicláveis.

O trabalho da ASMARE propicia o aumento da vida útil do aterro sanitário, a economia de recursos naturais e a limpeza urbana, além de garantir o sustento de famílias que sobrevivem dessa atividade.

Ademais, no dia 4 de outubro de 2012, foi realizada pelo Governo de Minas uma audiência pública com intuito de expor e debater a licitação de contrato de uma Parceria Publico-Privada (PPP) para o aproveitamento dos trabalhos de transporte, tratamento e acondicionamento final de RSU nos municípios da Região Metropolitana de Belo Horizonte (RMBH) e Colar Metropolitano. 
Diante dos fatos apresentados, o presente trabalho tem como problema norteador a seguinte pergunta: qual o valor percebido em negócios ambientais sob a ótica de agentes fomentadores do empreendedorismo na RMBH? Como objetivos específicos, pode-se destacar: a) Descrever o mercado de reciclagem no Brasil e em Minas Gerais, especialmente na RMBH; b) Descrever negócios ambientais e empreendedorismo ambiental na percepção de valor para negócios ambientais; c) Descrever fatores decisivos na montagem de negócios ambientais.

Dessa forma, uma das razões que justificam a existência desse trabalho é a importância da gestão empresarial que respeite as relações com o público e com meio ambiente, pela determinação de metas empresariais compatíveis com o desenvolvimento sustentável da sociedade, de maneira a preservar recursos ambientais para gerações futuras, respeitando a diversidade e promovendo o decréscimo das desigualdades sociais. Além disso, o momento para tratar do tema é oportuno, uma vez que o mercado está mais exigente quanto a uma política empresarial voltada para a preservação do meio ambiente. Sendo assim, avaliando também o baixo custo de realização do trabalho, a facilidade e o acesso a informações, bem como o tempo para a sua realização, aquele é considerado viável.

\section{Fundamentos de Negócios Ambientais}

\subsection{Reciclagem no Brasil e no Mundo}

Desde a década de 1980, a produção de embalagens e produtos descartáveis aumentou significativamente, assim como a produção de lixo, principalmente nos países desenvolvidos.

O processo de reciclagem possui como maior objetivo preservar o meio ambiente. A reciclagem contribui para a diminuição significativa da poluição do solo, da água e do ar. Muitas indústrias estão reciclando materiais como uma forma de reduzir os custos de produção.

Outro benefício da reciclagem é a quantidade de empregos que ela gera nas grandes cidades. Muitos desempregados estão buscando trabalho neste setor e conseguindo renda para manter suas famílias.

De acordo com o Instituto de Pesquisa Econômica Aplicada (IPEA, 2010), o Brasil perde cerca de $\mathrm{R} \$ 8$ bilhões por ano por deixar de reciclar os resíduos que poderiam ter outro fim, mas que são encaminhados aos aterros e lixões das cidades.

Se o homem souber reutilizar e assim desenvolver novos produtos, poderá ter, muito em breve, um mundo mais limpo e mais desenvolvido. Desta forma, será possível conquistar o tão sonhado desenvolvimento sustentável do planeta.

\subsection{SUSTENTABILIDADE URBANA}

Na década de 1970, surgiram diversas preocupações relacionadas ao meio ambiente. Fatores como poluição, exploração dos recursos naturais, aquecimento global e a baixa qualidade de vida da população.

Com o desenvolvimento e a urbanização rápida, as cidades vêm degradando todo o ambiente ao seu redor. Rios e outras fontes de água contaminadas, ar poluído, lixões expostos e desmatamentos são alguns exemplos dessa degradação. Todas essas práticas resultam em doenças, inundações, desmoronamentos e até mortes. E é a sociedade que está arcando com essas consequências.

Concentração de indústrias, crescimento acelerado das cidades, degradação ambiental fizeram com que houvesse a busca do desenvolvimento sustentável nas cidades. Assim, a sustentabilidade é um dos maiores desafios da sociedade contemporânea e de seus governantes, pois ao mesmo tempo em que é 
preciso continuar com o desenvolvimento econômico e social, é fundamental que essas ações tenham respeito com o meio ambiente.

Segundo Acserald (2001), para se adquirir a racionalidade eco-energética é necessário buscar uma maior eficiência no uso dos recursos naturais, igualdade no acesso aos serviços urbanos, estimulando a utilização de meios de transporte menos poluentes, aproximando-se do padrão da pureza. Para se alcançar uma cidade sustentável, é preciso atender três matrizes atuando em conjunto: a) Representação técnico-material da cidade; b) A cidade como espaço da "qualidade de vida"; c) A restauração da legitimidade das políticas urbanas.

\subsection{Tratamento de Resíduos nos Grandes Centros}

Entende-se como resíduos sólidos (RS) materiais nos estados sólidos e semi-sólidos, resultantes da atividade da sociedade de origem: industrial, doméstica, hospitalar, comercial, agrícola, de serviços e de varrição. Compreende lodos das Estações de Tratamento de Água (ETAS) e Estações de Tratamento de Esgoto (ETES), resíduos provenientes de equipamentos e instalações de controle da poluição e determinados líquidos, que devido às suas peculiaridades não possam ser descartados na rede de esgotos (DEBORTOLI; BORBA, 2006).

A gestão dos resíduos sólidos por políticas públicas requer um conhecimento específico da complexidade do sistema socioeconômico que dá origem a esses resíduos e de seus pontos críticos. No Brasil, os órgãos responsáveis pelo tratamento dos RS são as prefeituras municipais, enquanto as empresas e a sociedade têm a obrigação de auxiliar nesse gerenciamento, cobrando ações de melhoria.
Há inúmeras maneiras de se tratar e dispor os RS no meio ambiente, dentre elas as mais comuns são: a) Compostagem: processo aeróbio e controlado de reciclagem da matéria orgânica existente nos resíduos sólidos urbanos. A decomposição biológica e estabilização da matéria resulta em composto orgânico, cuja utilização no solo não oferece riscos ao meio ambiente (RUSSO, 2003); b) Aterro sanitário: processo pelo qual os resíduos são aterrados em um terreno devidamente preparado para essa finalidade. O solo deve ser protegido por uma manta isolante; dutos captadores de gases e um sistema de captação do chorume (líquido que sai do lixo) devem ser instalados. As camadas de lixo devem ser compactadas e cobertas com terra (EMBRAPA, 2004); c) Aterro controlado: nesse método, é feita apenas a cobertura do lixo com terra e proibida a entrada de pessoas não autorizadas. Essa prática não é tão eficiente quanto $o$ aterro sanitário, no entanto é melhor que o emprego dos antigos lixões (EMBRAPA, 2004); d) Incineração: processo consiste na combustão dos resíduos à alta temperatura, por meio de excesso de oxigênio, em que os materiais à base de carbono são decompostos, gerando calor. Este calor produzido também pode ser utilizado como forma de geração de energia elétrica e vapor, logo o processo de incineração também pode ser considerado como um processo de reciclagem da energia liberada na queima de materiais (ICLEI, 2010); e) Reciclagem: empregando diversas atividades integradas, esse método tem como princípio básico a remoção de materiais distintos, o tratamento e o retorno destes ao ciclo produtivo, diminuindo os volumes de resíduos a serem despejados nos aterros ou despachados a outros tipos de tratamentos finais, possibilitando, dessa forma, a redução de matéria-prima necessária aos processos produtivos industriais (ICLEI, 2010). 


\subsection{Cidades e o Consumo}

De acordo com BATISTA (2012), durante os anos 1960, 1970 e 1980 os espaços de consumo desenvolveram-se em sintonia com a fase de desenvolvimento urbano.

As transformações sociais ocorridas nas últimas décadas concederam ao consumo um papel protagonista no cotidiano dos indivíduos e das cidades que habitam. Essa realidade é intensa e visível, característica de uma sociedade cujos estilos de vida se orientam de forma muito significativa por valores e comportamentos ligados ao consumo de bens e serviços.

O protagonismo exercido pelo consumo no cotidiano das sociedades urbanas atribui aos centros comerciais um desempenho na organização da cidade, que é incontornável.

Sassen (1991) destaca que o domicílio é a principal unidade do consumo nas sociedades atuais. O aumento do número de residências, sobretudo das pequenas, induz a variações fundamentais na estrutura do consumo. A propagação da oferta de serviços residenciais que se observa nos centros urbanos atuais é somente um dos aspectos desta realidade.

O consumo afeta o ambiente, uma vez que recursos são extraídos da natureza em larga escala para abastecer as populações humanas com alimento ou energia. Esse efeito pode ser negativo, por exemplo: quando há subprodutos perigosos originados durante a produção ou consumo; bem como quando pela deposição de resíduos gerados no processo de consumo. Um exemplo hipotético seria a fabricação de um carro. Esta requer várias matérias-primas e origina uma gama de resíduos sólidos, líquidos e gasosos. Uma vez fabricados e nas mãos dos usuários, os carros consomem combustíveis fósseis, desprendendo poluentes na atmosfera. Além disso, seu uso também gera outros tipos de resíduos: óleos e fluidos usados, pneus descartados, baterias e peças que se desgastam e devem ser repostas. O próprio carro, por fim, carece ser descartado (ou reciclado) se e quando sua vida útil aproxima-se do fim. Esse método de produção e consumo interage com diversos fatores demográficos, sendo influenciado direta ou indiretamente: o envelhecimento ou rejuvenescimento da população, os arquétipos de formação de domicílio, a condição de chefia por idade, gênero e raça, o ciclo de vida das pessoas e dos próprios domicílios, entre outros (PEBLEY, 1998).

O protótipo de constituição de famílias e domicílios tem implicações sobre o consumo e por conseqüência sobre o meio-ambiente. Existem "custos ambientais fixos" de energia e água, produção e deposição de resíduos e emissão de esgoto, entre outros, na manutenção de uma casa ou residência. Esses custos, em um contexto de redução do tamanho médio das famílias, começam a ter maiores resultados sobre o ambiente e recursos naturais, visto que o aumento no número de casas provoca o aumento no consumo total e a perda de eficiência por economias de escala domésticas. Além disso, os gastos com necessidades domésticas básicas, como eletrodomésticos, transportes e alimentação, têm um perfil de idade, em que se observa um menor consumo em idades extremas (mais jovens e mais velhas) e elevado consumo nas idades médias. A ampliação do número de domicílios e a redução de seu tamanho são paralelas à multiplicação de famílias sem filhos, unipessoais e outras formas de disposições domiciliares, nas quais prevalecem pessoas em idades médias; como se vê, os dois efeitos competem para a redução da eficiência e o aumento da pressão sobre os recursos naturais e o ambiente (SAWYER 2002; MARTINE 2007).

Barbosa (2004) acredita que o crescimento populacional possui impacto evidente na geração de 
resíduos, inclusive, argumenta o autor, sobre o efeito notado pelo crescimento da renda:

(...) pesquisas indicam que cada $1 \%$ de aumento na renda per capita está associado com o aumento de $0,34 \%$ na geração de resíduos sólidos, enquanto cada $1 \%$ de aumento na população expande a geração de resíduos em 1,04\% (BARBOSA, 2004).

\subsection{EMPREENDEDORISMO AMBIENTAL}

A imprudente exploração dos recursos naturais, na escala da sociedade industrial de consumo de massas e sob uma expectativa imediata de geração de capital, tem afetado irremediavelmente a capacidade de suporte do ecossistema do planeta. O dilema entre o modelo de produção industrial para atender aos anseios ilimitados de consumo e a necessidade de uma exploração criteriosa da base natural evidenciaram o notório conceito de desenvolvimento sustentável. Sabe-se que o meio ambiente só será protegido se forem investidos recursos, tanto materiais como humanos, no desenvolvimento de atividades sustentáveis, e é nesse momento que surgem os empreendedores 'verdes', que ocupam seu tempo, recursos e ideias em projetos que apresentem à sociedade estilos sustentáveis de desenvolvimento econômico e social.

Agora, mais do que nunca, o verdadeiro desenvolvimento só é provável com responsabilidade e compromisso ambiental, então foi seguindo essa linha de pensamento que 0 Empreendedorismo Ambiental nasceu (ANTONIUS, 1999).

O empreendedorismo ambiental tem por finalidade promover ideias de negócios inovadoras na área do meio ambiente e, através da elaboração de um plano de negócio, desenvolver uma forma de redução dos riscos de investimentos da ideia. Sendo assim, procura alcançar um desenvolvimento mais sustentável condizente ao crescimento econômico, uma prioridade atual no contexto mundial.
Segundo Donaire (1999), as empresas, além de gerarem resultados econômico-financeiros, também devem se engajar em ações sociais e zelar pelo meio ambiente.

O mercado relacionado ao meio ambiente está em intenso crescimento, gerando inúmeras oportunidades dentro do ramo de negócios sustentáveis, proporcionando, de tal modo, algum tipo de benefício para o meio-ambiente, seja na prevenção ou na remediação de prejuízos originados pelas empresas.

O empreendedorismo ambiental auxilia na transformação de material descartado (lixo) em matéria-prima, assim como produtos naturais em lucros verdes, e a consolidar a visão de crescimento econômico por meio de um desenvolvimento sustentável, todavia, lucrativo.

\section{Novos Negócios Ambientals}

Enquanto o empreendedorismo tem seu foco na criação de valor econômico, o empreendedorismo sustentável amplia este objetivo e engloba também o desenvolvimento sustentável e seus benefícios sociais e ambientais. O conceito do empreendedorismo sustentável envolve, portanto, a identificação, criação e exploração de novos negócios que possibilitem ao empreendedor obter lucros a partir da solução de um problema ambiental e social. (BOSZCZOWSKI, 2012).

Como esclarece Zambon (2009), um empreendimento pode ser tido sustentável quando, além de considerar os impactos das suas atividades na sociedade, visa minimizar os possíveis impactos negativos em sua cadeia produtiva, sejam eles ambientais ou sociais.

O desenvolvimento de negócios sustentáveis provém da consciência dos líderes que estão à frente dos empreendimentos, além de uma sociedade cada vez mais consciente com o meio ambiente. 
A ampliação dos negócios sustentáveis possui um grande potencial de crescimento, decorrente de uma mudança cultural dos consumidores, exigindo maior responsabilidade social e ambiental das empresas e de uma mudança cultural dos empresários. As empresas ganham com a redução de custos de processos e da exposição da utilização de práticas ecologicamente corretas. Constata-se que, através de ações inovadoras a sustentabilidade empresarial, pode ser uma oportunidade de novos negócios. (RICCO, 2009)

A abertura de novos negócios apesar de ser ambientalmente limpa, possui uma geração significativa de diversos resíduos, quer sejam metais, papéis, papelões, plásticos, etc., e grande parte desses resíduos são oriundos dos processos de proteção aos delicados componentes de alta tecnologia. Os negócios ambientais tratam para desenvolver um novo conceito de embalagens para os produtos finais e para diminuir os impactos ambientais. Eles praticam programas de conscientização e comunicação das boas práticas ambientais tanto a comunidade interna, quanto à comunidade que vive em torno da empresa. Nessa comunicação, são abordados temas como a preservação dos recursos naturais, a redução da geração de resíduos, os cuidados com o solo, água e ar. A adoção das práticas ambientais proporciona às equipes uma reflexão quanto ao desperdício e racionamento de recursos. A empresa ganha então, a melhoria dos recursos e economia em setores produtivos. (RICCO, 2009)

Para abertura de negócios ambientais, deve-se assumir os seguintes compromissos: cumprir a legislação ambiental aplicável, as normas regulamentadoras e os demais requisitos subscritos pela Organização que se relacionem aos aspectos ambientais; prevenir a ocorrência de danos ambientais decorrentes de suas atividades buscando a utilização de tecnologias ambientalmente adequadas no gerenciamento dos processos e na concepção de novos produtos; estabelecer canais permanentes de comunicação das questões do meio ambiente com as partes interessadas; criar normas e registrar as ações relativas à conservação do meio ambiente de forma transparente; minimizar o consumo de água e energia; promover o treinamento e conscientização de seus colaboradores internos e externos para atuarem com responsabilidade na conservação do meio ambiente e na busca de melhorias contínuas; estabelecer, revisar e acompanhar, anualmente, os objetivos e metas ambientais específicos de suas atividades. (ZAMBON, 2009)

Segundo Pereira (2008) a expansão dos negócios que ajudem a reduzir danos ambientais e a exigência de melhor qualidade de vida são um sinal de transformação do mundo coorporativo. As preocupações relativas aos valores ambientais evoluíram, e os consumidores buscam produtos considerados ambientalmente saudáveis.

\section{Valor nOS Negócios}

Em todo negócio são encontrados e percebidos valores em relação à marca e ao tipo de atividade desenvolvida.

Segundo Tavares (2005), os valores servem como instrumento para avaliar e dar significado à busca da visão pelos participantes da organização. São eles que evitam que o senso de propósito seja imoral ou antiético. Os valores servem como padrão para avaliar e julgar programas e orientar decisões. Eles estabelecem a natureza e o sentido do vínculo entre a visão e a tomada de decisões. Ambas - visão e tomada de decisões - precisam ser apoiadas em valores para dar significado às ações dos membros organizacionais.

Há quase senso comum sobre quais valores devem guiar as ações das pessoas na maioria das 
organizações. Os valores que orientam, em termos gerais, a conduta de respeito a padrões de integridade pessoal, excelente técnica e ética profissional podem estar presentes nessa maioria. Ao longo do tempo, esses valores acabam por se traduzirem e se refletirem em diferentes culturas e em diferentes práticas organizacionais. Contudo, mesmo não sendo, ao todo, universais, devem resistir ao teste do tempo.

Outras vezes, segundo o autor, o termo valor parece bem redigido, mas não adiciona efetivamente valor $\mathrm{e}$ significado às ações das pessoas. Possuem o mesmo significado para negócios significativamente diferentes, tais como "qualidade é nossa tarefa número 1". As diferentes expectativas a serem atendidas requerem estratégias diferentes, mesmo quando o foco é qualidade, demandando, portanto, uma diferença de ênfase e mesmo de significado nos valores dos envolvidos. Seu reflexo no atendimento das expectativas dos vários públicos pode ser, assim, ilustrado.

Cliente: os consumidores preferirão empresas que declaram valores que eles acreditam e que efetivamente os implementam;

Empregados: os empregados sentem orgulho de sua empresa em virtude de seus valores, propósitos, sucesso passado e perspectivas futuras;

Fornecedores: darão preferência para as organizações que se apoiem em valores que consideram significativos e irão mostrar-se mais compreensivos em seus momentos de eventuais dificuldades financeiras;

Investidores: o zelo na aplicação de recursos e no retorno ao capital aplicado de terceiros, centrados em princípios éticos, faz com que a organização desfrute de sua preferência.

Integridade, respeito pelos funcionários, inovação ou serviço ao cliente são a argamassa para proporcionar a continuidade e consistência dessa multiciplicidade de ações, afirma Tavares (2005). Aplicam-se igualmente, além dos funcionários e clientes, a outras relações, como a comunidade, a imprensa, o governo. Todos eles demonstrarão maior respeito pelas ações e intenções explicitadas pela organização, quando centradas em valores compartilhados.

Em outra perspectiva, os valores são apresentados ao seu target como um elemento que pode posicionar e diferenciar seu negócio frente à concorrência. Segundo Kotler (2000), o produto ou serviço alcançará êxito se proporcionar valor e satisfação ao compradoralvo dentro de seus valores. O comprador escolhe entre diferentes ofertas com base naquilo que parece proporcionar o maior valor. $O$ autor explica que as empresas precisam encontrar novas maneiras de recuperar a confiança dos consumidores e de seus funcionários neste novo século. Hoje, mais do que nunca, as organizações precisam se certificar de que estão agindo corretamente e de que estão enviando mensagens honestas aos consumidores. Um número maior de empresas está realizando levantamentos sociais, desenvolvendo ações ambientais e criando laços efetivos de responsabilidade em seus negócios.

\section{Valor Percebido}

Segundo Kotler (2000), define-se valor como a razão entre o que o cliente recebe e o que ele dá, o qual recebe benefícios e assume custos. Aqueles incluem benefícios funcionais e emocionais. Segundo o autor, os custos incluem valores monetários, de tempo, de energia e psicológicos. O valor entregue ao cliente é a diferença real entre o valor total e o custo total para o cliente. O valor total para o cliente é o conjunto de benefícios que os clientes esperam de um determinado produto ou serviço, tendo em vista a promessa feita e o que realmente recebem. $O$ custo total para o cliente é o conjunto de custos em que os consumidores esperam incorrer para avaliar, obter, utilizar e descartar um produto ou serviço. 
Além do custo monetário, o custo total para o cliente inclui os custos de tempo, de energia física e psíquicos do comprador, que leva em conta esses gastos juntamente com o custo monetário para formar um quadro do custo total para o cliente. Os valores, segundo o autor, formam uma expectativa de valor e agem com base nela. A probabilidade de satisfação e repetição da compra, ou da percepção quanto ao valor da marca, depende de a oferta atender ou não a essa expectativa de valor ou sua associação com a mesma. (KOTLER, 2000).

\section{Metodologia}

O presente estudo constituiu-se da elaboração de uma investigação que foi feita através de pesquisas que, de acordo com Gil (2002), são um "procedimento racional e sistemático que tem como objetivo proporcionar respostas aos problemas que são propostos". Ainda esta pesquisa se caracterizou como qualitativa que, segundo Neves (1996), é direcionada ao longo de seu desenvolvimento e, em geral, não aplica instrumental estatístico para apreciação dos dados; seu alvo de interesse é vasto e tem como base uma perspectiva diferenciada. Nas pesquisas qualitativas, frequentemente o pesquisador procura entender os fenômenos, conforme a perspectiva dos envolvidos na situação estudada e, consequentemente, estabeleça sua interpretação dos fenômenos estudados.

Além disso, o estudo apresentou uma pesquisa descritiva que, segundo Vergara (2000), "expõe as características de determinada população ou fenômeno e estabelece correlações entre variáveis e define sua natureza." Ainda, a pesquisa não teve a obrigação de explicitar os fenômenos que descreveu, ainda que servissem de alicerce para tal esclarecimento.

A metodologia empregada neste estudo foi fundamentada em uma pesquisa de campo que, para
Lakatos e Marconi (2002), "consiste na observação de fatos e fenômenos tal como ocorrem espontaneamente, na coleta de dados a eles referentes e no registro de variáveis que se presumem relevantes, para analisá-los".

O levantamento de dados, etapa da pesquisa realizada para obter informações a respeito do assunto e investigar o tema sugerido buscando o conhecimento, foi realizado por meio de entrevista semiestruturada. Seguindo os preceitos de Hoffnagel (2003), a entrevista é vista como "uma constelação de eventos possíveis que se realizam como gêneros (ou subgêneros) diversos". As entrevistas foram direcionadas com objetivo de coletar dados através de entrevista semiestruturada. Os dados coletados foram analisados frente ao conteúdo, confrontando suas afirmativas.

\section{Resultados e Discussões}

As entrevistas foram conduzidas entre 25 de março e 06 de junho de 2013, dirigidas a um analista ambiental e ao vice-presidente de uma Organização Não Governamental do setor, ambos de empresas fomentadoras de negócios ambientais em Minas Gerais. Neste artigo, foram tratados como entrevistados A e B, respectivamente.

\subsection{ApResentAÇÃo dOS DADOS}

Ao serem questionados sobre o cenário atual do mercado de reciclagem para investimentos na região metropolitana de Belo Horizonte, os entrevistados afirmaram que as empresas de reciclagem que estão regularizadas quanto ao licenciamento ambiental são exemplos de investimentos sustentáveis. Mencionaram setores e quantidade das empresas de reciclagem em Minas Gerais: Depósitos (209), Metais (44), Plástico (29), Papel/Papelão (25), Borracha (15), Lâmpada (5), Bateria (3), Óleo Vegetal (3), Madeira 
(2). Isto reforça a afirmação do autor Donaire(1999), que afirma: o mercado relacionado ao meio ambiente está em intenso crescimento, gerando inúmeras oportunidades dentro do ramo de negócios sustentáveis, proporcionando, de tal modo, algum tipo de benefício para o meio-ambiente, seja na prevenção ou na remediação de prejuízos originados pelas empresas.

Ao ser questionado a respeito das oportunidades de negócios existentes na área de reciclagem na $\mathrm{RMBH}$, o entrevistado A se contrapôs à ideia de que atualmente alguns resíduos têm o potencial de serem explorados devido a sua disponibilidade e inexistência de empresas recicladoras e/ou processadoras na $\mathrm{RMBH}$, tais como: Vidro (garrafarias, planos, espelhos, automotivos, etc.); Recolhimento e reciclagem de óleo de cozinha; Recolhimento e reciclagem de madeira; Sacos de Cimento; Treinamentos de Reciclagem na Construção Civil. Isto confirma a proposição do entrevistado $\mathrm{B}, \mathrm{O}$ qual acredita que o crescimento populacional desordenado, aliado à ineficiência da iniciativa privada e à falta de estrutura pública para atender às demandas de bens e serviços básicos e necessários à sociedade, resultou em processo de degradação dos recursos naturais. $O$ crescente volume de resíduos sólidos descartados sem o destino adequado e as tentativas municipais em reverter este quadro através da coleta seletiva não são suficientes. De acordo com Debortoli e Borba (2006), os investimentos em novos negócios ambientais na área de reciclagem têm gerado resultados significativos na redução do montante de resíduos. Eles são realizados em nível nacional e estadual pelos municípios brasileiros como alternativa para a sustentabilidade das atividades econômicas, bem como a conscientização dos indivíduos sobre isso. Ambos entrevistados concordam que essas oportunidades de negócios estão crescendo e são de extrema importância para a sociedade.
Os entrevistados foram indagados sobre os investimentos, se são viáveis e lucrativos. Cautelosamente, o entrevistado B rebateu que existem vários critérios para esta especulação, mas a Lei 12.305/10 - Política Nacional de Resíduos Sólidos, que apresenta as diretrizes da não geração, redução, reuso, reciclagem, tratamento, disposição final dos rejeitos e possibilita oportunidades de negócios ambientais, incluindo a reciclagem.

De acordo com 0 entrevistado $A$, as metas empresariais podem ser compatíveis com o desenvolvimento sustentável da sociedade, porém primeiro deve-se conhecer as metas estabelecidas pelos órgãos ambientais de seu município, estado ou união e assim estabelecer e se comprometer a cumpri-las, de modo aplicado a sua realidade. Essas metas devem ser tangíveis e mensuráveis a fim de se avaliar a sua eficácia.

Segundo o entrevistado B, os fatores decisivos na montagem de negócios ambientais: Estudo do mercado existente (preços, concorrência); Custos com a implementação e operação (maquinários, licenciamento, energia, mão de obra, matéria-prima, etc.); Demanda de serviços ou produtos dos clientes (Volume, quantidade, frequência); Conhecer as legislações e as suas restrições e exigências; Exigências do Mercado (Sistema de gestão da Qualidade e Ambiental, rotulagem ambiental, etc.).

Ao serem questionados sobre conscientização da população os entrevistados declararam que nenhuma empresa ou entidade consegue conscientizar ambientalmente as pessoas. As empresas promovem ações para que isso aconteça. Não existe uma metodologia exata que garanta a conscientização, mas alguns pontos devem ser levados em consideração para a busca da sua eficácia. Ainda, o entrevistado A revelou-nos a importância das pesquisas na área de reciclagem para preservação ambiental com o objetivo de possibilitar a redução de: 
Resíduos em aterros, aumentando a vida útil dos mesmos; Utilização de matérias-primas no meio ambiente.

Investigou-se com entrevistados a percepção dos empreendedores a respeito da problemática ambiental e sobre a maneira como é percebido o valor das organizações ambientais por seus stakeholders. O entrevistado A respondeu que, hoje em dia, o empresário está compreendendo a legislação não como um problema ou restrição, e sim um critério que faz parte do seu negócio e que pode ser explorado a seu favor de forma competitiva no mercado atribuída a sua responsabilidade ambiental. Isso reforça a opinião do entrevistado $B$ a respeito do valor. Ele declarou que as empresas que têm um comprometimento em produzir de forma sustentável têm uma visibilidade e confiança dos seus clientes, investidores, dos órgãos ambientais, e da sociedade. Tais empreendimentos atendem às expectativas e exigências do mercado, o cumprimento dos requisitos legais, utilizando materiais reciclados em seus produtos, seus processos com consumo de água, energia e matéria-prima reduzido, realizando ações sociais dentro e fora da empresa.

O entrevistado A destacou a respeito de um projeto $\mathrm{e}$ ação social da Federação das Indústrias do Estado de Minas Gerais - FIEMG, onde disponibiliza dois programas gratuitos oferecidos para as empresas que tem o objetivo de promover negócios ambientais reduzindo custos e impactos ambientais, chamados Sistema Integrado de Bolsa de Resíduos - SIBR e Programa Mineiro de Simbiose Industrial - PMSI. O Sistema Integrado de Bolsa de Resíduos - SIBR é uma Plataforma virtual de negociação de resíduos, gratuita, que possibilita a empresa a criar anúncios de oferta, procura, troca e doação de resíduos. São destinados a empresas que possuem a regularização quanto ao licenciamento ambiental (Dispensa de LO, AAF, LO, LOC, LI). A Bolsa de Resíduos - SIBR também é um portal de referencia em resíduos, aberto ao público, dispondo de notícias, eventos, artigos técnicos de resíduos e cotação de preços de materiais recicláveis. O Programa Mineiro de Simbiose Industrial - PMSI é um projeto que visa identificar empresas e suas respectivas demandas, incentivando parcerias intersetoriais com foco em soluções ambientais. Esse programa funciona na forma de workshops presenciais, nos quais ocorrem rodadas de negócios. As empresas que participam dos workshops anunciam diversos recursos que podem ser: serviços, mão de obra especializada, equipamentos novos e usados, os resíduos, área física para instalação de empreendimentos terceirizados, etc.

\section{CONSIDERAÇÕES FINAIS}

A discussão a respeito do desenvolvimento sustentável se faz cada vez mais presente no dia a dia da população, assim, no sentido de provocar a reflexão sobre o assunto, especialmente sobre o modelo empreendedor adotado pela sociedade, este trabalho foi realizado.

O aumento da população no último século ligado ao uso não sustentável dos recursos naturais tem provocado o esgotamento destes últimos, e o crescimento acelerado da geração de resíduos das mais diferentes naturezas, as quais geraram um processo frequente de degradação do meio ambiente com graves implicações na qualidade de vida do homem.

Perante esse cenário em constante progresso foi desenvolvida a ideia de "Empreendedorismo Sustentável" acompanhada do conceito de "Reciclagem", o qual está diretamente ligado às ideias de "Reduzir" a produção de lixo e "Reaproveitar" os materiais utilizados.

O preceito da sustentabilidade exige ação conjunta e coordenada. Isso incide sobre a participação da sociedade, empresas e governos. Para o caso dos entrevistados esta pesquisa foi direcionada e, para 
tanto, buscou-se avaliar o cenário atual do mercado de reciclagem para investimentos na região metropolitana de Belo Horizonte e as oportunidades de negócios existentes na área de reciclagem na $\mathrm{RMBH}$, bem como a execução de ações empreendedoras mais sustentáveis.

Os investimentos em sustentabilidade também podem apresentar benefícios para as empresas e, desta forma, buscou-se focar na viabilidade dessas ações, procurando identificar como isso acontece e como pode colaborar para a legitimação e continuidade dos negócios.

$\mathrm{Na}$ esfera da pesquisa, pôde se averiguar, por meio de entrevista, o contexto avançado do empreendedorismo sustentável. Isso se deu pela visão holística, pela proatividade, pelos investimentos e, sobretudo, por que os novos empreendedores utilizam as mais reconhecidas tecnologias para inovar em seu modelo de negócio. Todas essas práticas sustentáveis têm proporcionado uma série de retornos para o empreendedor.

No sentido da sustentabilidade empresarial, os entrevistados demonstraram que, através de ações inovadoras de eco eficiência, a sustentabilidade empresarial pode ser uma oportunidade para novos negócios, gerando receita e contribuindo para a continuidade da empresa.
Tal fato confirma a teoria de Pereira (2008), na qual ele cita que "a incorporação da sustentabilidade nas estratégias empresariais é irreversível e atingirá todos os setores econômicos." Além disso, constata que essas oportunidades são reconhecidas quando o empreendedor relaciona seu conhecimento e experiência anterior sobre uma causa social ou ambiental aos meios de satisfazê-la (BOSZCWSKI, 2012).

Logo, conclui-se que o valor de negócios ambientais é cada vez mais percebido por parte dos empreendedores, uma vez que uma gestão comprometida com a sustentabilidade é oferecida como uma vantagem que pode posicionar e diferenciar os negócios frente à concorrência.

Ademais, uma gestão sustentável, que atende às perspectivas e requisitos do mercado, considerando a legislação vigente e que participem ativamente de ações sociais apresentam maior visibilidade, além de oferecerem mais confiança aos seus investidores, clientes, órgãos ambientais e a sociedade em si.

Os empreendedores atuais compreenderam que negócios ambientais podem ser explorados em seu benefício de maneira competitiva no mercado combinada à sua responsabilidade ambiental.

\section{REFERÊNCIAS}

ACSERALD, H. Desregulamentação, Contradições Espaciais e Sustentabilidade Urbana. Revista Paranaense de Desenvolvimento, Curitiba, n.107, p.25-38, jul/dez. 2004.

ANTONIUS, P. A. J. A. exploração dos recursos naturais face à sustentabilidade e gestão ambiental: uma reflexão teórica conceitual. Belém: NAEA, 1999.

BARBOSA. L. T. Gerenciamento de Resíduos Sólidos Urbanos no Norte de Minas Gerais: Estudo Relativo à Implantação de Unidades de Reciclagem e
Compostagem a partir de 1997. Dissertação (mestrado), Programa de Pós-graduação em Saneamento, Meio Ambiente e Recursos Hídricos. Escola de Engenharia - UFMG, 2004.

BATISTA, L. M. M. A. cidade e o consumo: o desempenho dos centros comerciais "down-town" numa perspectiva social e urbana. 1998. Número de folhas f. Dissertação de Mestrado - Universidade do Porto, Cidade do Porto, 2012. 
BOSZCZOWSKI, A. M. O empreendedorismo sustentável e o processo empreendedor: Em busca de oportunidades de novos negócios como solução para problemas sociais e ambientais. 2011. $27 \mathrm{f}$. Dissertação de Mestrado - Universidade Federal do Paraná, Curitiba, 2012.

DEBORTOLI, R.; BORBA, J. A. Análise do Tratamento dos Resíduos Sólidos e dos Benefícios Ambientais e Econômicos da Coleta Seletiva: O caso dos catadores de Biguaçu-SC. 2006. 14 f. Artigo Acadêmico Universidade Federal de Santa Catarina, Florianópolis, 2006.

DONAIRE, D. Gestão ambiental na empresa. 2. ed. São Paulo: Atlas, 1999.

EMBRAPA MEIO-NORTE. Tratamento de resíduos Sólidos. Teresina, 2004. Disponível em < http://www.cpamn.embrapa.br/publicacoes/folders/200 4/textoresiduos.pdf>. Acesso em: 6 nov. 2012.

FEAM. Novos Dados da Disposição de Resíduos Sólidos Urbanos em Minas. Belo Horizonte, 2010. Disponível em $<$ http://www.feam.br/index2.php?option=com_cnt ent\&do_pdf=1\&id=581 >. Acesso em: 28 set. 2012.

GIL, A. C. Como Elaborar Projetos de Pesquisa. 4. ed. São Paulo: Atlas, 2002. 175 p. ISBN 85-224-3169-8.

HOFFNAGEL, J. C. (Org.) Gêneros textuais, tipificação e interação. São Paulo: Cortez, 2005. 165 p.

ICLEI RESÍDUOS. Tratamento e Destinação. São Paulo, 2011. Disponível em < http://www.iclei.org.br/residuos/?page_id=356>.

Acesso em: 6 out. 2012.

IPEA. Brasil perde $R \$ 8$ bilhões por não reciclar. Brasil. 2010. Disponível em < http://www.ipea.gov.br/sites/000/17/edicoes/61/pdfs/rd 61 sec01.pdf>. Acesso em: 5 nov. 2012.

KOTLER, Philip. - Administração de Marketing - 10ª Edição, 7aㅗ reimpressão - São Paulo: Prentice Hall, 2000.

LAKATOS, E. M; MARCONI, M. A. Técnicas de Pesquisa: planejamento e execução de pesquisas, amostragens e técnicas de pesquisas, elaboração, análise e interpretação de dados. 5 ed. São Paulo: Atlas, 2002. 282 p. ISBN 85-224-3263-4.
MARTINE, G. O lugar do espaço na equação população/meio ambiente. Revista Brasileira de Estudos de População. vol. 24(2), 2007.

NEVES, J. L. Caderno de Pesquisa em Administração. São Paulo, V.1, n 3, 1996.

PEBLEY, A. R. "Demography and the Environment." Demography, Vol. 35, No. 4, pp. 377-389, 1998.

PEREIRA, A. M. Os impactos ambientais $e$ as oportunidades de negócios: estudos de caso. 2008. 13f. Artigo Acadêmico - UNICAMP, São Pauilo, 2008.

PIMENTEL, N. Reciclagem e Meio Ambiente. Jornal do Comércio, Manaus, 19 out. 2008.

RICCO, A. S. Sustentabilidade Empresarial: Uma Oportunidade para Novos Negócios. 2009. 15f. Artigo Técnico - Faculdade Estácio de Sá, Vitória, 2009. Disponível em < http://www.craes.org.br/arquivo/artigoTecnico/Artigos Sustentabilidade_Empresaria_Uma_oportunidade_par a_novos_negciosl.pdf>. Acesso em: 6 nov. 2012

RUSSO, M. A. T. Tratamento de Resíduos Sólidos. 2003. 196 f. Artigo Acadêmico - Universidade de Coimbra, Coimbra, 2003.

SASSEN, S. The global city: New York, London, Tokyo. Princenton: Princenton University, 1991.

SAWYER, D. Population and Sustainable Consumption in Brazil. In: HOGAN, D. J.BERQUÓ, E.; COSTA H. S. M. (eds.). Population and environment in Brazil: Rio + 10. Campinas: CNPD, ABEP, NEPO, 2002.

TAVARES, M. C. Gestão estratégica. 2. ed. São Paulo: Atlas, 2005. 440 p. ISBN 8522439419.

VERGARA, S. C. Projetos e Relatórios de Pesquisa em Administração. 3. ed. São Paulo: Atlas, 2000. 92 p. ISBN 85-224-2623-6.

ZAMBON, B. P. Sustentabilidade Empresarial: Uma Oportunidade para Novos Negócios. 2009. 15f.Artigo Técnico - Faculdade Estácio de Sá, Vitória, 2009. Disponível em http://www.craes.org.br/arquivo/artigoTecnico/Artigos Sustentabilidade_Empresaria_Uma_oportunidade_par a_novos_negciosl.pdf>. Acesso em: 6 nov. 2012. 